\title{
Transtemporal approach to hypothalamic hamartomas in children: report of 3 cases
}

\author{
*Adikarige H. D. Silva, MPhil, FRCS, William B. Lo, MA, FRCS, Nilesh R. Mundil, FRCS, and \\ A. Richard Walsh, MA, FRCS \\ Department of Neurosurgery, Birmingham Children's Hospital, Birmingham Women and Children's NHS Foundation Trust, \\ Birmingham, United Kingdom
}

\begin{abstract}
The surgical approach to hypothalamic hamartomas $(\mathrm{HHs})$ associated with medically refractory epilepsy is challenging because of these lesions' deep midline or paramedian location. Whether the aim is resection or disconnection, the surgical corridor dictates how complete a procedure can be achieved. Here, the authors report a transtemporal approach suitable for Delalande type I, inferior extraventricular component of type III, and type IV lesions. This approach provides optimal visualization of the plane between the hamartoma and the hypothalamus with no manipulation to the pituitary stalk and brainstem, allowing for extensive disconnection while minimizing injury to adjacent neurovascular structures.

Through a 1-cm corticectomy in the middle temporal gyrus, a surgical tract is developed under neuronavigational guidance toward the plane of intended disconnection. On reaching the mesial temporal pia-arachnoid margin, it is opened, providing direct visualization of the hamartoma, which is then disconnected or resected as indicated. Critical neurovascular structures are generally not exposed through this approach and are preserved if encountered.

Three patients (mean age 4.9 years) with intractable epilepsy were treated using this technique as part of the national Children's Epilepsy Surgery Service. Following resection, the patient in case 1 (Delalande type I) is seizure free off medication at 3 years' follow-up (Engel class IA). The patient in case 2 (Delalande type III) initially underwent partial disconnection through a transcallosal interforniceal approach and at first had significant seizure improvement before the seizures worsened in frequency and type. Complete disconnection of the residual lesion was achieved using the transtemporal approach, rendering this patient seizure free off medication at 14 months postsurgery (Engel class IA). The patient in case 3 (Delalande type IV) underwent incomplete disconnection with a substantial reduction in seizure frequency at 3 years' follow-up (Engel class IIIC). There were no surgical complications in any of the cases.

The transtemporal approach is a safe and effective alternative to more conventional surgical approaches in managing HHs with intractable epilepsy.
\end{abstract}

https://thejns.org/doi/abs/10.3171/2019.12.PEDS19231

KEYWORDS hypothalamic hamartoma; epilepsy; transtemporal approach; surgical technique; congenital

$\mathrm{H}$ YPOTHALAMIC hamartomas (HHs) are rare, benign congenital malformations consisting of a mixture of glial cells and neurons resembling normal hypothalamus. ${ }^{9}$ They appear as nodules along the wall or floor of the third ventricle or can be attached to the mammillary bodies or tuber cinereum, making resection challenging. ${ }^{11}$

Primary epileptogenesis arises from the hamartoma substance itself ${ }^{15,20}$ giving rise to the well-described hypothalamic seizures; alternately, seizure activity can spread to adjacent cortical structures such as the frontal and temporal lobes, which then act as secondary foci of epileptogenesis. ${ }^{5,16,17}$ The epilepsy syndrome typically consists of gelastic or dacrystic seizures with frequent progression to a more generalized epileptic "encephalopathy" characterized by both partial and generalized seizures, cognitive decline, and behavioral dysfunction. ${ }^{4}$ Furthermore, HHs are often associated with hypothalamic-pituitary axis disturbance. Thus, they carry a significant functional burden. Because they are frequently refractory to anticonvulsant therapy, early intervention is increasingly advocated to achieve seizure control and potentially reverse the cognitive-behavioral dysfunction. ${ }^{29}$

Hypothalamic hamartomas are generally classified based on their anatomical relationship to surrounding

ABBREVIATIONS GnRH = gonadotropin-releasing hormone; $\mathrm{HH}=$ hypothalamic hamartoma. SUBMITTED April 24, 2019. ACCEPTED December 6, 2019.

${ }^{*}$ A.H.D.S. and W.B.L. contributed equally to this work and share first authorship. 
TABLE 1. Summary of the Delalande and Fohlen classification for HHs

\begin{tabular}{ccc}
\hline Type & \multicolumn{1}{c}{ Characteristics } & Surgical Approach \\
\hline I & $\begin{array}{c}\text { Horizontal plane of insertion \& lateralized orientation to } \\
\text { hypothalamus; no intraventricular component }\end{array}$ & Pterional approach for complete disconnection \\
\hline II & $\begin{array}{c}\text { Vertical plane of insertion \& orientation to hypothalamus; } \\
\text { usually intraventricular extension }\end{array}$ & Endoscopic or open microsurgical intraventricular approach \\
\hline III & Combines features of types I \& II & $\begin{array}{c}\text { 2-stage approach often required for complete disconnection; endoscopic or open } \\
\text { microsurgical intraventricular approach for intraventricular component; pterional } \\
\text { approach for extraventricular component }\end{array}$ \\
\hline IV & Giant hamartoma that does not fit into any other subtype & No specific surgical strategy; combination of techniques required for disconnection \\
\hline
\end{tabular}

Table is based on the classification scheme presented in Delalande O, Fohlen M: Disconnecting surgical treatment of hypothalamic hamartoma in children and adults with refractory epilepsy and proposal of a new classification. Neurol Med Chir (Tokyo) 43:61-68, 2003.

structures and their size., ${ }^{1,7}$ The most commonly used Delalande classification is based on the plane of insertion on the hypothalamus and its implication on the surgical approach (Table 1).

While precocious puberty can be successfully managed with gonadotropin-releasing hormone $(\mathrm{GnRH})$ analogs, ${ }^{26}$ epilepsy is more refractory to conventional medical thera$\mathrm{py}^{2}{ }^{2}$ Various therapeutic interventions have been described over the years, including microsurgery performed using various surgical approaches, stereotactic strategies, and, more recently, stereotactic laser interstitial therapy. ${ }^{18,29,40}$ This variety reflects the inadequacy of any single strategy in addressing the fundamental aim of achieving seizure control within an acceptable time frame and at no or limited cost to the patient's functional status.

Surgery remains an effective modality for seizures caused by $\mathrm{HH} .{ }^{38}$ Microsurgery is divided into predominantly vertical disconnection approached from superiorly or transverse disconnection approached from inferiorly. The chosen strategy is determined by the location and extension of the lesion..$^{10}$ For predominantly intraventricular lesions (Delalande type II and intraventricular component of type III), transventricular vertical disconnection techniques include the open transcortical intraventricular and midline interhemispheric transcallosal (anterior interforniceal [TAIF], transforaminal, transchoroidal) approaches. Rarely, a subfrontal interhemispheric translamina terminalis approach to the third ventricle is used. Endoscopic surgery is also used in smaller, intraventricular (type III and intraventricular part of type III), and residual lesions. By contrast, transverse disconnection approaches from inferiorly are advocated for predominantly extraventricular/ paraventricular lesions (Delalande type I, extraventricular component of type III, and type IV) with a variety of techniques all involving an extension or variation of a pterional craniotomy and utilizing a common subfrontal approach. These include orbitozygomatic, pterional, subtemporal, and supraorbital techniques as well as a subfrontal technique through the lamina terminalis. ${ }^{18,38}$

The goal of surgical intervention in many early series was complete resection of the hamartoma. ${ }^{24,25,32}$ Stereotactic electroencephalography (EEG) depth electrode recordings showed that gelastic seizures arise from within the lesion, and seizure remission was achieved by the removal of all HH tissue. ${ }^{15,27}$ Given the deep location of the hamartoma, however, resection can be associated with a significant risk of injury to adjacent structures. An alternative strategy is disconnecting the hamartoma from its surrounding limbic connections, in particular the anterior thalamic nucleus, mammillary bodies, and anterior cingulate gyrus. ${ }^{3}$ The success of disconnective strategies applied in the context of epilepsy has been demonstrated in hemispherotomy as opposed to hemispherectomy. ${ }^{37}$ Delalande reported seizure freedom in 8 of 17 patients who had undergone open and/or endoscopic disconnection. ${ }^{7,9}$ The effectiveness of stereotactic techniques such as laser interstitial therapies relies on, and therefore also supports, the mechanism of the disconnective strategy. ${ }^{12,22,29,40}$

We have developed a transtemporal technique, which provides an excellent approach to the plane of disconnection or resection with early visualization of the hamartoma and avoidance of surrounding neurovascular structures. In this paper, we describe the technique as well as the results of 3 cases and recommend it as a first-line surgical approach in selected patients, namely those with Delalande type I, inferior extraventricular component of type III, and type IV lesions.

\section{Methods}

We prospectively monitored 3 patients with medically refractory epilepsy associated with $\mathrm{HH}$ who had undergone surgery in our department between January 2014 and November 2017. All 3 patients were assessed within the national Children's Epilepsy Surgery Service. They underwent thorough neurological and endocrinological assessment complemented by neuropsychological evaluation. Standard EEG and video telemetry excluded alternative primary foci of epileptogenesis. All 3 patients underwent transtemporal surgery as described below. All patients were followed up at 6 months and annually thereafter.

\section{Surgical Technique}

The patient is positioned supine with the head turned contralaterally with minimal lateral flexion. The head is fixed in pins or rested on a horseshoe head ring, depending on the patient's age. Frameless stereotactic image guidance (Medtronic StealthStation S7 AxiEM) is used to aid throughout the disconnection/resection.

A standard temporal craniotomy is performed with exposure of the sylvian fissure and superior and middle temporal gyri. A 1 - to $1.5-\mathrm{cm}$ corticectomy is made in 


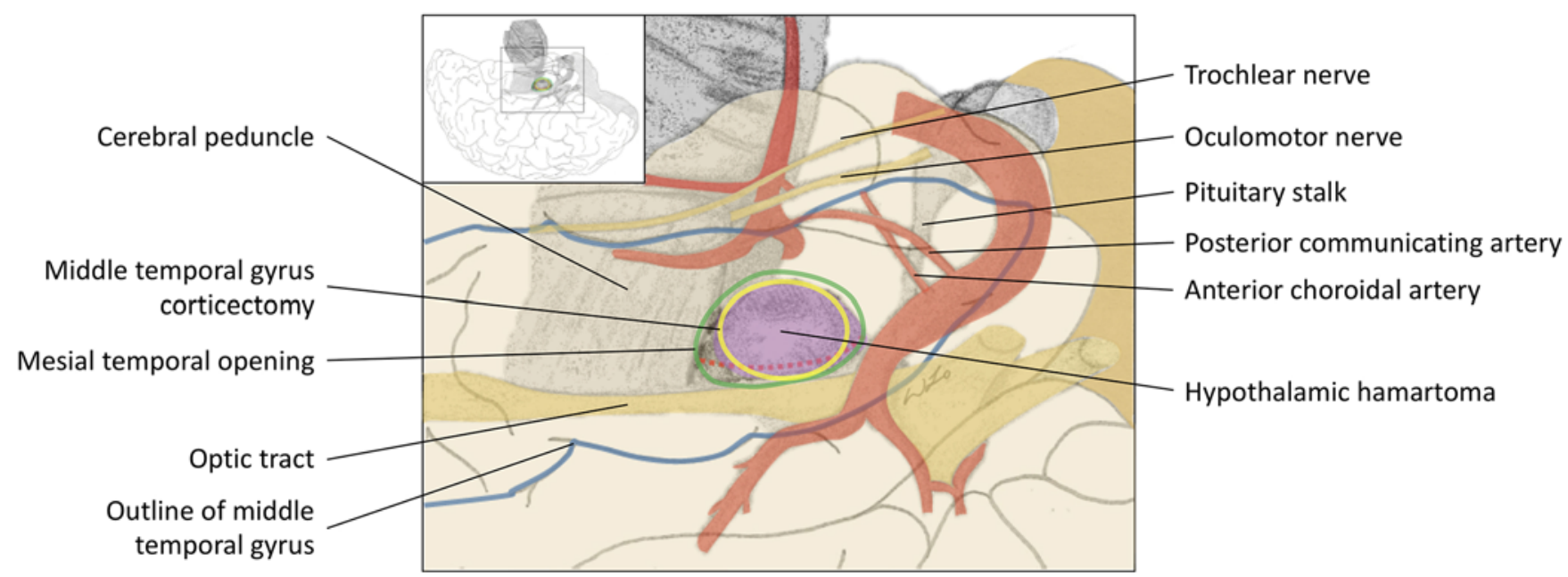

FIG. 1. Illustration showing a left-sided transtemporal operative approach. The main image is the enlarged view of the inset, included for orientation. Both images depict the view of the brain laterally from the left, with the head turned $10^{\circ}$ to the left, so that the slightly posteriorly oriented surgical tract is perpendicular to the page. The relevant arteries appear in red; the relevant cranial nerves appear in yellow; the brain is pale yellow; the brainstem (and cerebral peduncle) and pituitary gland are gray. Not all contralateral structures are included. The middle temporal gyrus is marked by the blue line, and the superficial surface corticectomy is marked by the yellow line. The mesial temporal opening, and thus access to the $\mathrm{HH}$ (purple), is marked by the green line. Note that the mesial operative area plus the opening is larger than the superficial surface corticectomy. The line of disconnection of the hamartoma from the hypothalamus is marked with the red dotted line. Copyright William B. Lo. Published with permission. Figure is available in color online only.

the middle temporal gyrus approximately $3.5-4 \mathrm{~cm}$ from the temporal pole (Fig. 1 inset). With suction, a surgical tract is developed from the corticectomy directly to the line of attachment of the hamartoma-our intended plane of disconnection/resection. Therefore, the tract traverses the middle temporal neocortex, white matter, and part of the amygdala (which forms the anterior part of the uncus and is resected in subpial fashion) to reach the mesial piaarachnoid (Figs. 1 and 2). The temporal horn, which often lies $3 \mathrm{~cm}$ posterior to the anterior tip of the temporal pole and $2-3 \mathrm{~cm}$ deep, may occasionally need to be opened in large hamartomas, but the hippocampus, whose head forms the posterior part of the uncus, is preserved and never transgressed. Following the principle of microsurgery, the deep microscopic operative field is $1.5-2 \mathrm{~cm}$ wider than the superficial corticectomy.

After opening of the translucent mesial pia-arachnoid, the hamartoma along with its base is visualized (Figs. 1 and 3). This is confirmed using neuronavigation. Typically, type I and the inferior or extraventricular component of type III HHs project into the interpeduncular cistern owing to their origin from the third ventricular floor, tuber cinereum, and mammillary body(ies). The chiasmatic, carotid, and crural cisterns may be compressed and overlying the lesion in the anteroposterior direction. On the exposed lateral surface of the lesion, the anterior to posterior line of $\mathrm{HH}$ attachment, and therefore the intended plane of disconnection/resection, is coagulated and the lesion is entered. The disconnection is performed using a combination of suction or ultrasonic aspiration, until the circumferential (i.e., medial, anterior, and posterior) pial surface is encountered. This thin structure should be preserved, although this is not always possible. It indicates the extent of disconnection and avoids manipulation of surrounding structures. In resective cases, a wider opening is made over the lateral lesion surface from the previous disconnection line, also performed with suction and ultrasonic aspiration.

The direct surgical route toward the $\mathrm{HH}$ means that most neurovascular structures are not exposed or disturbed (Fig. 1). Superiorly, the optic tract is out of the operative field. Inferiorly, in our experience, the oculomotor nerve, posterior communicating artery, and anterior choroidal artery are not routinely encountered and are sometimes displaced inferiorly. Anteromedially, the resection limit leads to the chiasmatic cistern. The pituitary stalk is not visualized or is identified at a safe distance. The optic chiasm is not involved. Posteriorly, the cerebral peduncle of the brainstem, as well as the posterior cerebral arteries and basilar artery complex, is sometimes juxtaposed against the lesion and encountered toward the end of the disconnection. They are well protected especially if the pial surface overlying the hamartoma is preserved. There is also a compressed layer of arachnoid in the crural cistern. Similarly, the basal vein of Rosenthal situated superoposteriorly is not exposed.

In large hamartomas (type IV), the pituitary stalk and brainstem may be visualized anteriorly and posteriorly, respectively. These structures are encountered toward the end of the procedure and are preserved. In hamartomas with bilateral attachment, the contralateral hamartoma can also be disconnected or resected through this approach from one side. In these cases, beyond the contralateral border of the $\mathrm{HH}$ is the contralateral cisternal space and its content structures.

\section{Case Reports}

Case 1

This boy, age 2 years and 3 months, had a left-sided Delalande type I HH (Fig. 4A-C). His first seizure oc- 

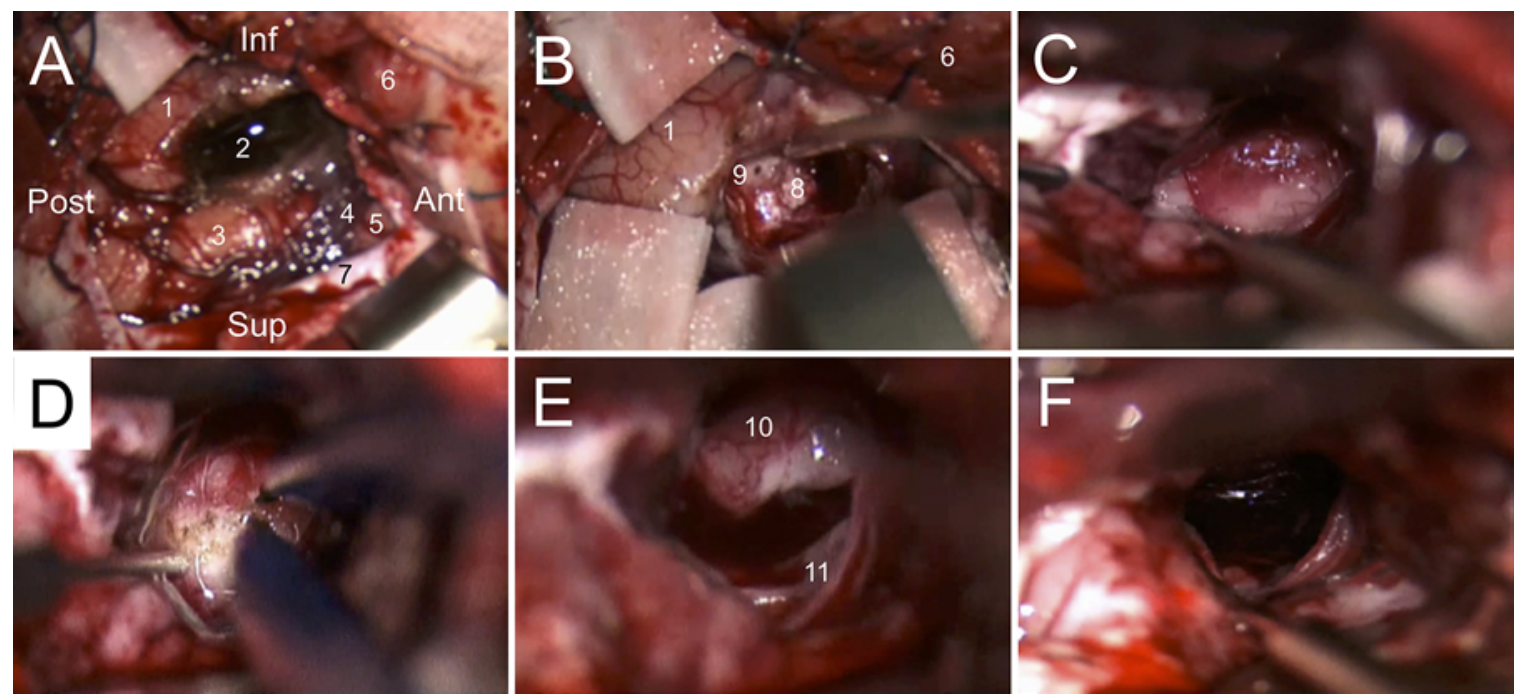

FIG. 2. Case 1. Intraoperative microscopic photographs demonstrating the surgical steps of a left transtemporal resection of a Delalande type I HH. Note that this is the surgeon's view and that the superior part of the brain is toward the bottom of all images. A: Low-magnification photograph showing a middle temporal gyrus corticectomy (2), exposed inferior and superior temporal gyri (1 and 3, respectively), and sylvian fissure (4). B: Medium-magnification photograph demonstrating dissection of the white matter (8) and the deeper gray amygdala (9). The mesial pia bank is just visible immediately to the right of label 9. C: High-magnification view showing the lateral surface of the $\mathrm{HH}$. Note the glistening layer comprising the lesion membrane and arachnoid tissue. D: Bipolar coagulation is performed along the line of disconnection, through which the lesion is entered. E: Disconnection is completed all across the plane of attachment, leaving the bulk of the $\mathrm{HH}$ in situ. The pia-arachnoid superior to the disconnection line (11) is visible. If resection is the aim, then the lesion is removed piecemeal, preserving the surface membrane where possible. $\mathrm{F}$ : The $\mathrm{HH}$ has been removed completely. Ant = anterior; Inf = inferior; Post = posterior; Sup = superior; 4 = sylvian fissure and vessels; $5=$ inferior frontal gyrus; $6=$ reflected temporalis muscle; $7=$ reflected dural flap; $10=\mathrm{HH}$ following disconnection. Figure is available in color online only.

curred at 8 months of age. Preoperatively, he had 4-5 gelastic seizures per day. He also had severe global developmental delay, lying below the first percentile on cognitive, language, and motor subtests. He was seizure free following resection and was successfully weaned off anticonvulsants by 3 years' follow-up, attaining an Engel class IA outcome. There was sustained and significant improvement in his global development and cognitive function.

Case 2

This boy, age 6 years and 7 months, had a right-sided
Delalande type III HH. He had experienced seizures since birth, had a background of Pallister-Hall syndrome and severe global developmental delay, and was diagnosed with precocious puberty at 12 months of age, which was treated with GnRH analog. At the age of 3 years and 2 months, he underwent partial disconnection of the intraventricular component of the hamartoma via a right transcallosal interforniceal approach. The frequency of his gelastic seizures decreased from more than 100 a day to 2-3 daily episodes. There was concomitant improvement in his aggression, impulsivity, and learning ability.
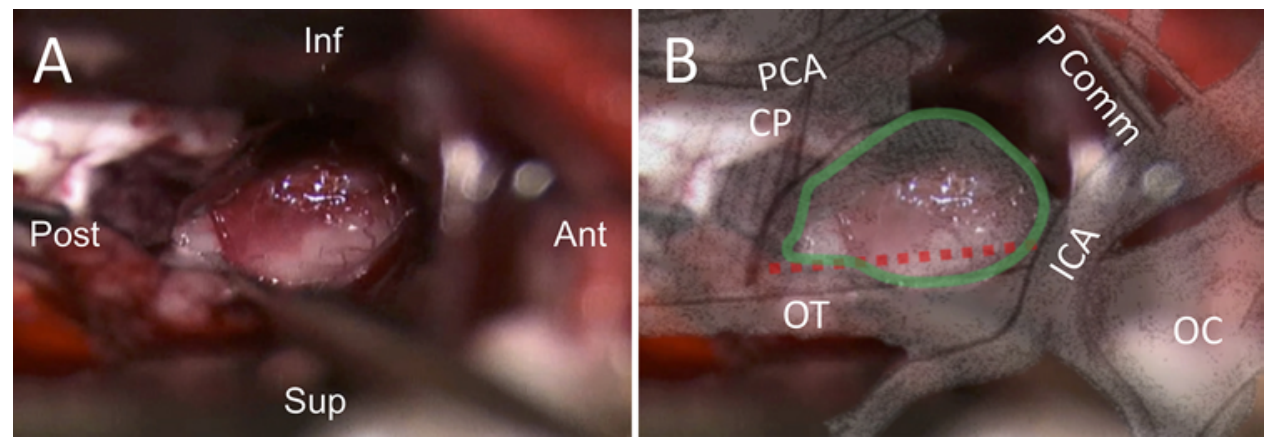

FIG. 3. Case 1. A: Intraoperative microscopic photograph of the HH through the corticectomy. B: The same photograph is superimposed over a diagram depicting the lesion and surrounding structures. The green line marks the surgical exposure through the deep mesial temporal opening. The red dotted line marks the line of disconnection. Note how the approach directs the surgeon to the lesion with minimal disturbance to surrounding neurovascular structures. $\mathrm{CP}=$ cerebral peduncle; ICA = internal carotid artery; $\mathrm{OC}=$ optic chiasm; $\mathrm{OT}=$ optic tract; $\mathrm{P}$ Comm = posterior communicating artery; $\mathrm{PCA}=$ posterior cerebral artery. Figure is available in color online only. 

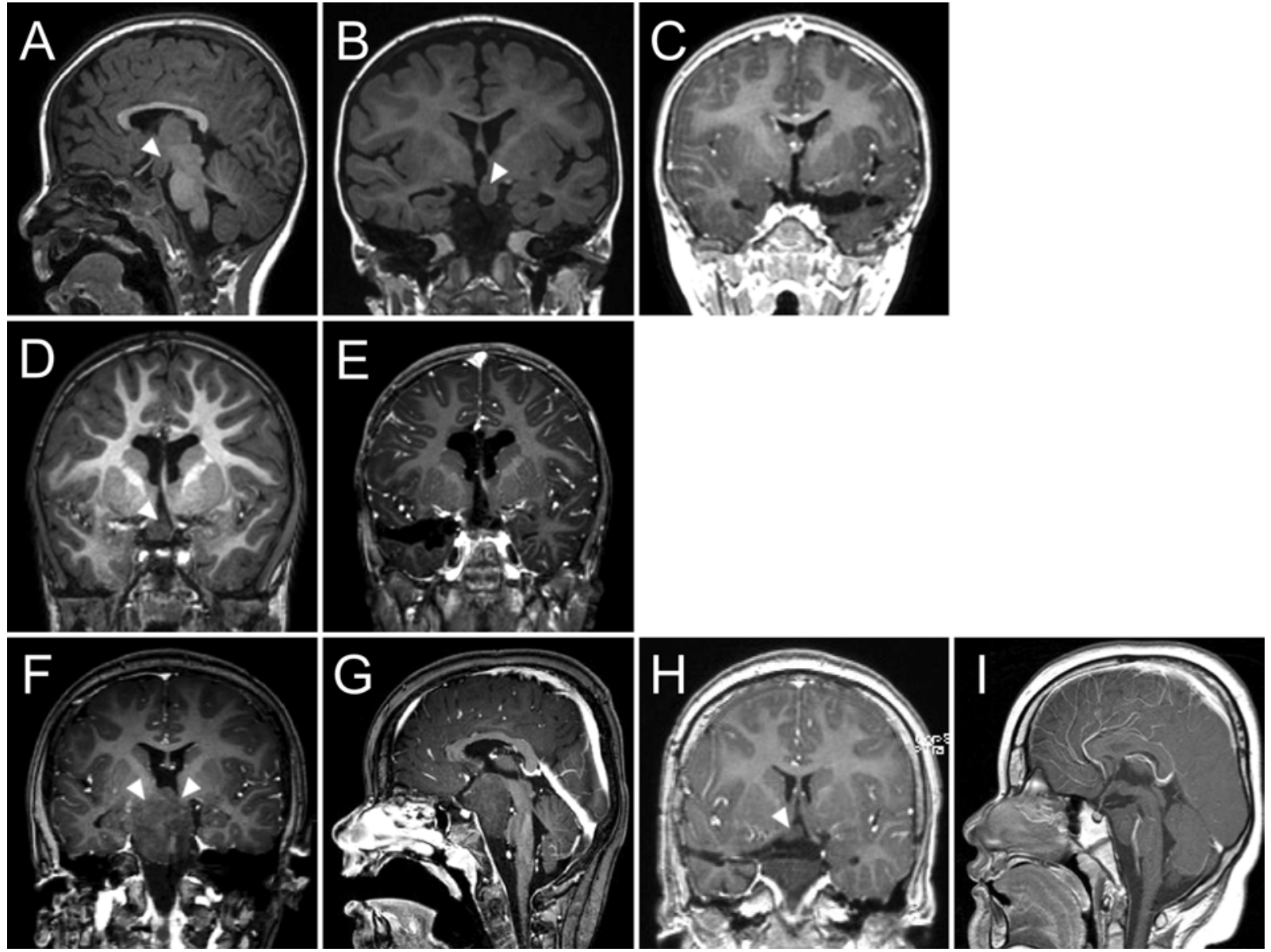

FIG. 4. Case 1. Preoperative sagittal (A) and coronal (B) MR images showing a left Delalande type I lesion. Arrowheads indicate the origin of the $\mathrm{HH}$. Postoperative coronal image (C) showing the surgical tract and complete excision of the $\mathrm{HH}$ via a left transtemporal approach. Case 2. Preoperative (D) and postoperative (E) coronal MR images obtained in a patient who underwent disconnection surgery of the inferior component of a right Delalande type III lesion. Evidence of a previous right transcallosal approach is visible. Arrowhead indicates the residual connection. Case 3. Preoperative coronal (F) and sagittal (G) MR images obtained in a patient with a type IV, i.e., giant, $\mathrm{HH}$, showing bilateral hypothalamic attachments (arrowheads). Postoperative MR images $(\mathbf{H}$ and $\mathbf{I})$ obtained after a right transtemporal surgery, showing complete disconnection on the left and a small residual right-sided intraventricular component (arrowhead).

After 18 months, however, seizure frequency increased to 3-10 gelastic seizures a day. He also started to have infrequent generalized tonic-clonic seizures. There was an associated behavioral and cognitive decline. He subsequently underwent completion of the disconnection via the transtemporal approach (Fig. 4D and E). At 14 months' follow-up, he had no further seizures (Engel class IA) and was off anticonvulsants. He also demonstrated significant improvement in his social interactions, with markedly less aggressive behavior in particular.

\section{Case 3}

This boy, age 5 years and 3 months, had a Delalande type IV giant $\mathrm{HH}$ with bilateral hypothalamic attachments, with a right-sided prominence. He had initially presented with significant weight gain and had been diagnosed with precocious puberty at 12 months old, requiring $\mathrm{GnRH}$ analog treatment, and developed seizures at 24 months. He had 5 gelastic and 5 generalized tonic-clonic seizures daily. He underwent right-sided transtempo- ral surgery. Complete disconnection on the left side was achieved. On the right side, a residual intraventricular component could not be resected or disconnected given limitations due to the size and superior extent of the $\mathrm{HH}$ (Fig. 4F-I). He was initially seizure free for 4 months before his seizures recurred but at a substantially reduced frequency of 1 gelastic seizure every 2-3 days at 3 years' follow-up (Engel class IIIC). There has been no significant change in his behavior or cognitive ability.

There were no surgical complications in any of the 3 cases, no postoperative visual field defect, and no further pituitary function impairment. Tables 2 and 3 summarize preoperative clinical characteristics and postoperative surgical outcomes in our patients, respectively.

\section{Discussion}

\section{Current Treatment Modalities and Surgical Strategy for HHs}

Treatment modality and surgical strategy have evolved 
TABLE 2. Summary of clinical data on 3 patients with HH treated via the transtemporal approach

\begin{tabular}{|c|c|c|c|c|c|c|c|}
\hline $\begin{array}{l}\text { Case } \\
\text { No. }\end{array}$ & Sex & $\begin{array}{c}\text { Age at } \\
\text { Seizure Onset }\end{array}$ & Type \& No. of Seizures & $\begin{array}{l}\text { Endocrinology } \\
\qquad \text { (age) }\end{array}$ & Neuropsychology \& Behavior & $\begin{array}{l}\text { Delalande } \\
\text { Type }\end{array}$ & $\begin{array}{c}\text { No. of } \\
\text { Ops }\end{array}$ \\
\hline 1 & M & $8 \mathrm{mos}$ & GSs, 4-5/day & No dysfunction & Global developmental delay & I & 1 \\
\hline 2 & M & Since birth & $\begin{array}{l}\text { Before 1st surgery: GSs, >100/ } \\
\text { day; before } 2 \text { nd surgery: GSs, } \\
\text { 3-10/day; GTCSs, infrequent }\end{array}$ & $\begin{array}{l}\text { Precocious } \\
\text { puberty (1 yr) }\end{array}$ & $\begin{array}{l}\text { Global developmental delay; learning dif- } \\
\text { ficulties }\end{array}$ & III & 2 \\
\hline 3 & M & $2 \mathrm{yrs}$ & GSs, 5/day; GTCSs, 5/day & $\begin{array}{l}\text { Precocious } \\
\text { puberty (1 yr), } \\
\text { obesity }\end{array}$ & $\begin{array}{l}\text { Normal development until } 2 \text { yrs; profound de- } \\
\text { terioration \& regression w/ developmental } \\
\text { delay, autism, \& learning difficulties }\end{array}$ & IV & 1 \\
\hline
\end{tabular}

GS = gelastic seizure; GTCS = generalized tonic-clonic seizure .

in $\mathrm{HH}$ management. ${ }^{18}$ Previously, it was believed that complete or near-complete resection was required to achieve seizure control. ${ }^{27}$ Currently, the consensus is that disconnection of the hamartoma from its surrounding structures, in particular the mammillary bodies, is equally effective $^{7,12,22}$ while minimizing surgical morbidity, especially endocrine disturbances and vascular injuries. The widely used Delalande classification ${ }^{7}$ is based on location as related to the ventricle, attachment, and size of the HH. It also offers appropriate surgical approaches for each category.

Vertical disconnection approaches from superiorly (open or endoscopic intraventricular-transcortical or interhemispheric transcallosal) are well suited to Delalande type II lesions and, as a staged procedure, to the intraventricular component of type III lesions. ${ }^{38}$ Limitations include the width of the interforniceal corridor (with the attendant risk of memory dysfunction), the difficulty in disconnecting lesions with bilateral attachments, and the depth of the surgical tract, which can preclude resection of the inferior-most component of the hamartoma. Large intraventricular hamartomas can prove difficult to manipulate.

By contrast, skull base approaches (pterional, orbitozygomatic, subtemporal, or subfrontal) are advocated for predominantly extraventricular hamartomas (Delalande type I, extraventricular type III, and type IV). However, they do not provide a natural line of approach to the plane of disconnection of the hamartoma from the third ventricular floor, and thus they provide suboptimal visualization, in particular of the posterior margin. ${ }^{8}$ Furthermore, in all the aforementioned approaches, the final surgical corridor to the hamartoma is via a combination of the opticocarotid triangle, the lamina terminalis, and between the optic nerves, requiring manipulation, dissection, and operating within a constricted working space between critical neurovascular structures. ${ }^{38}$ This increases the likelihood of incomplete disconnection and neurological or endocrinological complications.

Over the last decade, nonsurgical treatment modalities have been increasingly used to treat HHs. ${ }^{18}$ Stereotactic lesioning includes noninvasive Gamma Knife radiosurgery and minimally invasive radiofrequency thermocoagulation and MRI-guided laser interstitial therapy. ${ }^{29,30,40}$ The main advantage of such procedures is the avoidance of the surgical complications attached to open resective/disconnective surgery. The disadvantage is the delayed onset of action, late neurodevelopmental effects from radiosur- gery on the child's brain, radiation to surrounding critical structures, and the theoretical risk of malignancy. ${ }^{30}$ In selected patients, as guided by the classification proposed by Régis et al., radiosurgery is as effective as microsurgery or should be considered as part of a two-stage treatment. ${ }^{29,30}$ Our technique is also a useful alternative to MRI-guided laser interstitial therapy, ${ }^{40}$ which is not routinely available in the United Kingdom, is invasive, and has been associated with intracranial hemorrhages, although it has a more immediate onset of action in comparison to stereotactic radiosurgery.

A recent review summarizes the benefits and disadvantages of both surgical and nonsurgical treatment modalities in the management of epilepsy related to HHs. ${ }^{18}$ In our practice, we advocate resection/disconnection especially in Delalande type I, II, and III lesions. Surgery is also considered primarily in Delalande type IV lesions. In situations in which surgical approaches are inadequate or the risk-benefit ratio is unfavorable-predominantly Delalande type IV and Régis types I-III-radiosurgery has provided a safe and efficacious alternative even though its onset of action can be delayed by several months. We do not have any experience with stereotactic laser interstitial therapy, although we recognize that it is increasingly used for all types of HHs and would consider it as equivalent to surgery as an option.

\section{Transtemporal Approach}

The presented transtemporal approach is based on identification of the plane of attachment of the hamartoma to the hypothalamus, also the plane of disconnection. The middle temporal gyrus approach, as commonly used for a standard anterior temporal lobectomy, provides a safe surgical corridor to that line of attachment with early visualization of the hamartoma and its anteroposterior plane of disconnection and minimal disturbance to surrounding neurovascular structures. It is similar to the transtemporal transchoroidal approach described by Hamlat and colleagues for diencephalo-mesencephalic lesions within the retrochiasmatic space. ${ }^{13}$ Their technique is built on the work of others who have described approaches to access this difficult region. ${ }^{13,14,31,36}$ Five cases were included in their series, one of which was an $\mathrm{HH}$ treated for precocious puberty but not for epilepsy. For more anteriorly located lesions, the authors performed a transamygdala extension in addition to the transchoroidal approach. Hypothalamic 
hamartomas occur in a typical region related to the anterior third ventricular floor. Therefore, we recommend a direct transamygdala trajectory, which is more suited to the specific location, avoids entry into the temporal horn, and does not compromise the hippocampus. In all of our cases, no previously mentioned critical neurovascular structures were manipulated. Only the pituitary stalk and brainstem have been visualized.

When the hamartoma has bilateral attachments to the hypothalamus, the transtemporal approach allows for a safe contralateral disconnection by stopping at the pial surface on the far side of the hamartoma, protecting the contralateral temporal lobe and optic tract. The approach is particularly well suited to hamartomas with a broad unilateral or bilateral attachment to the hypothalamus and thus can be applied to giant lesions as well.

Disadvantages of our approach include the need to perform a corticectomy and partial resection of the middle temporal gyrus and amygdala. In this series, there was no The hippocampus was preserved in all cases.

\section{Role of Neuronavigation}

Our technique relies on a good working knowledge of the topographic anatomy of the temporal lobe, temporal horn, and basal cisterns. ${ }^{13,39}$ Neuronavigation is a critical adjunct in planning the optimal trajectory through the middle temporal gyrus and mesial temporal structures and avoiding critical neurovascular structures. It is also helpful in confirming the hamartoma attachment and thus the disconnection line. Neuronavigation is reliable, as the mesial structures are minimally affected by "brain shift." If neuronavigation is lost during surgery, the action plan depends on the stage at which this loss happens. If it is during the approach stage, one should abandon the procedure and obtain a repeat navigation scan for redo surgery. If the lesion has been clearly identified when navigation is lost, one can continue the resection/disconnection. In all 3 cases, neuronavigation was maintained throughout surgery.

\section{Surgical Outcomes}

We report on a series of 3 patients (Delalande types I, III, and IV) who underwent microsurgical resection or disconnection via the transtemporal approach. A comprehensive comparison of clinical outcomes in the current series with those in the literature is difficult because of the relatively small case numbers $(\leq 5)$ in most series. ${ }^{19,21,23,28 \text {, }}$ 33-35 The medium-term seizure-freedom rate of our transtemporal series (67\% Engel class IA) is similar to or better than those in similarly sized series ${ }^{6,8}$ and larger series utilizing a pterional approach or a modification. ${ }^{7,27,38}$ There was also improvement in behavior and cognitive function in 2 of the patients. There were no surgical, neurological, or endocrinological complications.

\section{Conclusions}

Surgical disconnection or resection of $\mathrm{HH}$ is challenging because of its deep midline or paramedian location and lack of clearly defined anatomical margins between the lesion and surrounding structures. Surgical approaches need specific complication related to the temporal dissection.

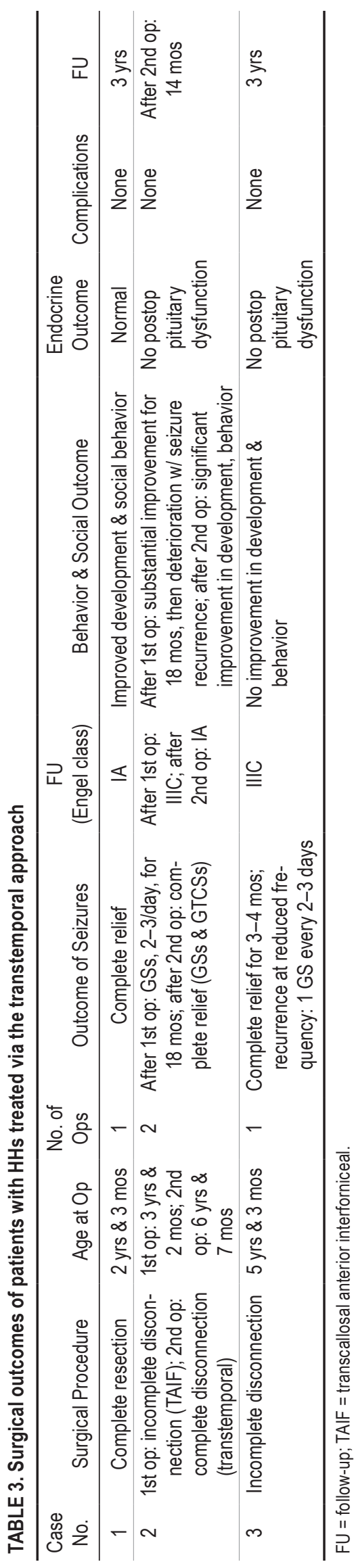




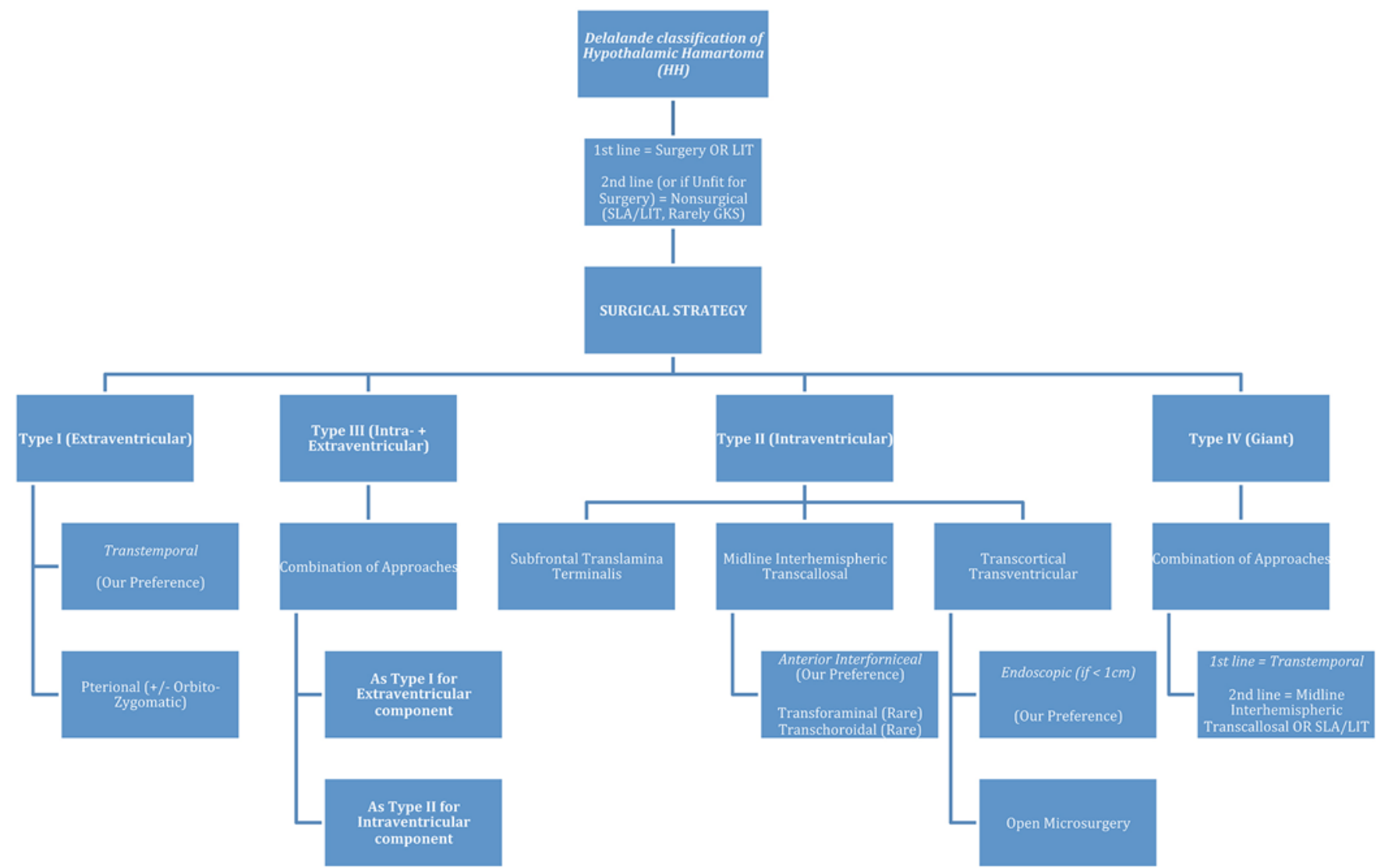

FIG. 5. Framework for surgical approaches to HHs based on the Delalande classification. Surgery was considered as first-line therapy in all patients with HHs in the absence of routine availability of laser interstitial therapy, as in the United Kingdom. However, with emerging results, we consider it equally with surgery in all patients. GKS = Gamma Knife surgery; LIT = laser interstitial therapy; SLA = stereotactic laser ablation. Figure is available in color online only.

to be tailored to the lesion location and size. We propose that the transtemporal approach is a suitable alternative in approaching Delalande type I, inferior extraventricular type III, and type IV (as part of a combination strategy) HHs (Fig. 5). It provides a more direct and clearer surgical corridor, better angle and visualization of the plane of disconnection, and minimal manipulation or displacement of neurovascular structures. Our early results of 3 patients show that it is a safe and effective technique, and further evaluation should be conducted in a larger number of cases.

\section{References}

1. Arita K, Ikawa F, Kurisu K, Sumida M, Harada K, Uozumi T, et al: The relationship between magnetic resonance imaging findings and clinical manifestations of hypothalamic hamartoma. J Neurosurg 91:212-220, 1999

2. Arita K, Kurisu K, Kiura Y, Iida K, Otsubo H: Hypothalamic hamartoma. Neurol Med Chir (Tokyo) 45:221-231, 2005

3. Arroyo S, Lesser RP, Gordon B, Uematsu S, Hart J, Schwerdt $P$, et al: Mirth, laughter and gelastic seizures. Brain 116:757780, 1993

4. Berkovic SF, Andermann F, Melanson D, Ethier RE, Feindel W, Gloor P: Hypothalamic hamartomas and ictal laughter: evolution of a characteristic epileptic syndrome and diagnostic value of magnetic resonance imaging. Ann Neurol 23:429-439, 1988
5. Cascino GD, Andermann F, Berkovic SF, Kuzniecky RI, Sharbrough FW, Keene DL, et al: Gelastic seizures and hypothalamic hamartomas: evaluation of patients undergoing chronic intracranial EEG monitoring and outcome of surgical treatment. Neurology 43:747-750, 1993

6. Choi JU, Yang KH, Kim TG, Chang JH, Chang JW, Lee BI, et al: Endoscopic disconnection for hypothalamic hamartoma with intractable seizure. Report of four cases. J Neurosurg 100 (5 Suppl Pediatrics):506-511, 2004

7. Delalande O, Fohlen M: Disconnecting surgical treatment of hypothalamic hamartoma in children and adults with refractory epilepsy and proposal of a new classification. Neurol Med Chir (Tokyo) 43:61-68, 2003

8. Feiz-Erfan I, Horn EM, Rekate HL, Spetzler RF, Ng YT, Rosenfeld JV, et al: Surgical strategies for approaching hypothalamic hamartomas causing gelastic seizures in the pediatric population: transventricular compared with skull base approaches. J Neurosurg 103 (4 Suppl):325-332, 2005

9. Fohlen M, Lellouch A, Delalande O: Hypothalamic hamartoma with refractory epilepsy: surgical procedures and results in 18 patients. Epileptic Disord 5:267-273, 2003

10. Frazier JL, Goodwin CR, Ahn ES, Jallo GI: A review on the management of epilepsy associated with hypothalamic hamartomas. Childs Nerv Syst 25:423-432, 2009

11. Freeman JL, Coleman LT, Wellard RM, Kean MJ, Rosenfeld JV, Jackson GD, et al: MR imaging and spectroscopic study of epileptogenic hypothalamic hamartomas: analysis of 72 cases. AJNR Am J Neuroradiol 25:450-462, 2004

12. Freeman JL, Harvey AS, Rosenfeld JV, Wrennall JA, Bailey 
CA, Berkovic SF: Generalized epilepsy in hypothalamic hamartoma: evolution and postoperative resolution. Neurology 60:762-767, 2003

13. Hamlat A, Morandi X, Riffaud L, Carsin-Nicol B, Haegelen $\mathrm{C}$, Helal H, et al: Transtemporal-transchoroidal approach and its transamygdala extension to the posterior chiasmatic cistern and diencephalo-mesencephalic lesions. Acta Neurochir (Wien) 150:317-328, 2008

14. Heros RC, Lee SH: The combined pterional/anterior temporal approach for aneurysms of the upper basilar complex: technical report. Neurosurgery 33:244-251, 1993

15. Kahane P, Ryvlin P, Hoffmann D, Minotti L, Benabid AL: From hypothalamic hamartoma to cortex: what can be learnt from depth recordings and stimulation? Epileptic Disord 5:205-217, 2003

16. Kerrigan JF, Ng YT, Chung S, Rekate HL: The hypothalamic hamartoma: a model of subcortical epileptogenesis and encephalopathy. Semin Pediatr Neurol 12:119-131, 2005

17. Kerrigan JF, Parsons A, Tsang C, Simeone K, Coons S, Wu J: Hypothalamic hamartoma: neuropathology and epileptogenesis. Epilepsia 58 (Suppl 2):22-31, 2017

18. Khawaja AM, Pati S, Ng YT: Management of epilepsy due to hypothalamic hamartomas. Pediatr Neurol 75:29-42, 2017

19. Kramer U, Spector S, Nasser W, Siomin V, Fried I, Constantini S: Surgical treatment of hypothalamic hamartoma and refractory seizures: a case report and review of the literature. Pediatr Neurosurg 34:40-42, 2001

20. Kuzniecky R, Guthrie B, Mountz J, Bebin M, Faught E, Gilliam F, et al: Intrinsic epileptogenesis of hypothalamic hamartomas in gelastic epilepsy. Ann Neurol 42:60-67, 1997

21. Majchrzak K, Bierzyńska-Macyszyn G, Bobek-Billewicz B, Majchrzak H, Ładziński P: Rare primary tumours of the hypothalamus in adults: clinical course and surgical treatment. Neurol Neurochir Pol 44:546-553, 2010

22. Mathieu D, Kondziolka D, Niranjan A, Flickinger J, Lunsford LD: Gamma knife radiosurgery for refractory epilepsy caused by hypothalamic hamartomas. Stereotact Funct Neurosurg 84:82-87, 2006

23. Miranda P, Esparza J, Cabrera A, Hinojosa J: Giant hypothalamic hamartoma operated through subfrontal approach with orbitary rim osteotomy. Pediatr Neurosurg 42:254-257, 2006

24. Nishio S, Fujiwara S, Aiko Y, Takeshita I, Fukui M: Hypothalamic hamartoma. Report of two cases. J Neurosurg 70:640-645, 1989

25. Nishio S, Morioka T, Fukui M, Goto Y: Surgical treatment of intractable seizures due to hypothalamic hamartoma. Epilepsia 35:514-519, 1994

26. Oostdijk W, Hümmelink R, Odink RJ, Partsch CJ, Drop SL, Lorenzen F, et al: Treatment of children with central precocious puberty by a slow-release gonadotropin-releasing hormone agonist. Eur J Pediatr 149:308-313, 1990

27. Palmini A, Chandler C, Andermann F, Costa Da Costa J, Paglioli-Neto E, Polkey C, et al: Resection of the lesion in patients with hypothalamic hamartomas and catastrophic epilepsy. Neurology 58:1338-1347, 2002

28. Pati S, Abla AA, Rekate HL, Ng YT: Repeat surgery for hypothalamic hamartoma in refractory epilepsy. Neurosurg Focus 30(2):E3, 2011

29. Régis J, Scavarda D, Tamura M, Nagayi M, Villeneuve N, Bartolomei F, et al: Epilepsy related to hypothalamic hamartomas: surgical management with special reference to gamma knife surgery. Childs Nerv Syst 22:881-895, 2006

30. Régis J, Scavarda D, Tamura M, Villeneuve N, Bartolomei F, Brue T, et al: Gamma knife surgery for epilepsy related to hypothalamic hamartomas. Semin Pediatr Neurol 14:73-79, 2007
31. Rhoton AL Jr: The supratentorial cranial space: microsurgical anatomy and surgical approaches. Neurosurgery 51 (4 Suppl):S1-iii-S1-vi, 2002

32. Rosenfeld JV, Harvey AS, Wrennall J, Zacharin M, Berkovic SF: Transcallosal resection of hypothalamic hamartomas, with control of seizures, in children with gelastic epilepsy. Neurosurgery 48:108-118, 2001

33. Roszkowski M, Wolska A, Drabik K, Grajkowska W: [Surgical treatment of GnRH secretory hypothalamic hamartomas causing precocious puberty.] Neurol Neurochir Pol 33:587602, 1999 (Polish)

34. Siomin V, Spektor S, Beni-Adani L, Constantini S: Application of the orbito-cranial approach in pediatric neurosurgery. Childs Nerv Syst 17:612-617, 2001

35. Stewart L, Steinbok P, Daaboul J: Role of surgical resection in the treatment of hypothalamic hamartomas causing precocious puberty. Report of six cases. J Neurosurg 88:340-345, 1998

36. Ulm AJ, Tanriover N, Kawashima M, Campero A, Bova FJ, Rhoton A Jr: Microsurgical approaches to the perimesencephalic cisterns and related segments of the posterior cerebral artery: comparison using a novel application of image guidance. Neurosurgery 54:1313-1328, 2004

37. Villemure JG, Vernet O, Delalande O: Hemispheric disconnection: callosotomy and hemispherotomy. Adv Tech Stand Neurosurg 26:25-78, 2000

38. Wait SD, Abla AA, Killory BD, Nakaji P, Rekate HL: Surgical approaches to hypothalamic hamartomas. Neurosurg Focus 30(2):E2, 2011

39. Wen HT, Rhoton AL Jr, de Oliveira E, Cardoso AC, Tedeschi $\mathrm{H}$, Baccanelli M, et al: Microsurgical anatomy of the temporal lobe: part 1: mesial temporal lobe anatomy and its vascular relationships as applied to amygdalohippocampectomy. Neurosurgery 45:549-592, 1999

40. Xu DS, Chen T, Hlubek RJ, Bristol RE, Smith KA, Ponce FA, et al: Magnetic resonance imaging-guided laser interstitial thermal therapy for the treatment of hypothalamic hamartomas: a retrospective review. Neurosurgery 83:1183-1192, 2018

\section{Disclosures}

The authors report no conflict of interest concerning the materials or methods used in this study or the findings specified in this paper.

\section{Author Contributions}

Conception and design: Silva. Acquisition of data: Silva, Walsh. Analysis and interpretation of data: Silva. Drafting the article: Silva. Critically revising the article: all authors. Reviewed submitted version of manuscript: Silva, Walsh. Approved the final version of the manuscript on behalf of all authors: Silva. Administrative/technical/material support: Lo. Study supervision: Walsh. Senior surgeon: Walsh.

\section{Supplemental Information \\ Previous Presentations}

The contents of this paper were presented as an oral presentation at the Annual Meeting of the International Society for Pediatric Neurosurgery (ISPN) held in Tel Aviv, Israel, on October 7-11, 2018.

\section{Correspondence}

Adikarige H. D. Silva: Birmingham Children's Hospital, Birmingham, United Kingdom. dulankasilva@googlemail.com. 